\title{
O ESTUDO DA CIDADE E DO CIDADÃO: A CLASSE COMO INTERVENÇÃO DIDÁTICA PARA ENSINAR GEOGRAFIA
}

\author{
EL ESTUDIO DE LA CIUDAD Y LOS CIUDADANOS: LA \\ CLASE COMO UNA INTERVENCIÓN DE ENSEÑANZA \\ PARA ENSEÑAR A LA GEOGRAFÍA
}

\author{
THE CITY AND CITIZEN STUDY: THE CLASS AS \\ DIDACTIC INTERVENTION TO TEACH GEOGRAPHY
}

\author{
Ana Claudia Ramos Sacramento ${ }^{1}$ \\ Universidade de Estado de Rio de Janeiro, Brasil
}

\section{RESUMO}

O objetivo deste artigo é discutir como as aulas de Geografia, a partir de uma didática histórico-crítica, pode ser pensada como um referencial teórico sobre os conteúdos e conceitos de cidade e de urbano. Compreender o mundo atual tem sido o desafio dos docentes na escola básica, pois diferentes recursos didáticos, conceitos e metodologias têm surgido ou emergido para repensar os caminhos de mediar o conhecimento. A partir da metodologia de pesquisa da etnografia escolar buscamos compreender o espaço da aula de sala e como construir formas de ensinar de maneira crítica e reflexiva. As atividades apresentadas foram realizadas em turmas de $2^{\circ}$ e $3^{\circ}$ anos do Ensino Médio, em duas escolas públicas do Estado do Rio de Janeiro. Os resultados mostram que ao trabalhar com esta concepção didática, os estudantes se tornam sujeitos ativos.

1 Acadêmica, Universidad de Estado de Rio de Janeiro - Brasil-BR. Correo eletrócnico: anaclaudia.sacramento@hotmail.com 
Ana Claudia Ramos Sacramento. El estudio de la ciudad y los ciudadanos: la clase como una intervención de enseñanza para enseñar a la geografía

Palavras-chaves: cidade, urbano, cidadão, ensino de geografia, didática histórico-crítica.

\title{
RESUMEN
}

El propósito de este artículo es discutir cómo las lecciones de geografía de una enseñanza históricocrítico puede ser considerados como un marco teórico sobre los contenidos y conceptos de ciudad y urbana. Comprender el mundo de hoy ha sido el reto de los maestros de las escuelas primarias, ya que diferentes recursos para enseñar conceptos y metodologías han surgido o emergido para repensar las formas de mediación de conocimientos. A partir de la metodología de investigación de la etnografía escolar pretendemos entender el espacio de la clase habitación y la forma de construir formas de enseñar de forma crítica y reflexiva. Las actividades presentadas se llevaron a cabo en las clases de segundo y tercero años de dos escuelas secundarias en dos escuelas públicas en el estado de Río de Janeiro. Los resultados muestran que cuando se trabaja con este diseño didáctico, los estudiantes se convierten en sujetos activos.

Palabras clave: ciudad, urbe, ciudadano, enseñanza de la geografía, didáctica histórico-crítica.

\begin{abstract}
The objective of this article is to discuss how the classes of Geography, based on a historical-critical didactics, can be thought of as a theoretical reference on the contents and concepts of city and urban. Understanding the current world has been the challenge of teachers in basic school, because different didactic resources, concepts and methodologies have emerged or emerged to rethink the ways of mediate knowledge. From the research methodology of school ethnography we seek to understand the space of classroom and how to construct ways of teaching in a critical and reflective way. The activities presented were carried out in 2nd and 3rd grade classes at two public schools in the State of Rio de Janeiro. The results show that in working with this didactic concept, students become active subjects.
\end{abstract}

Keyword: City, urban, citizen, geography teaching, historical-critical didactics

\section{Introdução}

Podemos dizer que a escola do século XXI tem sofrido exigências diariamente para que seus estudantes tenham novas formas de conteúdo, novos valores, novas concepções de mundo, devido às questões globais como a homogeneização dos espaços, e ao mesmo tempo as desigualdades sociais, socioeconômicas, socioambientais; a violência, o desemprego e tantos outros problemas que estão no espaço e fazem parte da construção social de um país e outros que promovem impactos nas vidas cotidianas.

Sendo assim, as novas concepções nos permitem pensar como são as práticas cotidianas das pessoas e suas relações com o lugar vivido. Para tanto, a formação da cidadania tem de ser uma prática comum de construção e reconstrução de conhecimentos, capacidade e valores, assim como as práticas socioespaciais dos estudantes, que caminham, circulam e conhecem partes das cidades que têm as vivências dos problemas que ocorrem nelas. 
A instituição escolar tem o papel de promover o conhecimento das disciplinas escolares, a fim de formar cidadãos capazes de ler os fenômenos espacializados no mundo vivido, que são construídos nas mediações didáticas, como nas aulas, em que os professores devem buscar dialogar com os conhecimentos cotidianos científicos para desenvolver uma aprendizagem significativa para os estudantes.

Desta forma, o objetivo deste trabalho é analisar como as aulas mediadas a partir da didática histórico-crítica constrói o entendimento dos estudantes do ensino médio acerca das temáticas de cidade e de urbano. Sabendo-se que a cidade é um tema estudado nos currículos de várias partes do mundo, mas que muitas vezes não é trabalhado como conteúdo dos outros conteúdos, ou seja, quando se trabalha os elementos físicos, não há a articulação com a cidade, ou quando se trabalha com a população, não se discute efetivamente as relações com a cidade.

Quanto à metodologia, este trabalho está articulado à pesquisa qualitativa, sendo o foco a abordagem da etnografia escolar cuja análise será a partir da construção das aulas de Geografia em três turmas de $2^{\circ}$ ano do ensino médio, com a participação de cem estudantes. Estas aulas foram realizadas em uma escola federal localizada no município de Seropédica, nos períodos de 2014; como também em uma escola estadual localizada no município de São Gonçalo no período de 2015, em que se trabalhou com três turmas do $3^{\circ}$ ano, totalizando cem estudantes. Além destes, houve a participação de três professoras. Vale destacar que ambas as escolas estão localizadas no estado do Rio de Janeiro.

Assim, esta pesquisa busca descrever, compreender e interpretar os fenômenos educativos presentes no contexto escolar. De acordo com o que Franco e Ghedin (2008) analisam, cada escola tem um contexto, uma comunidade diferenciada, que estimula um tipo de sentido e de significado para as suas ações educativas.

A pesquisa etnográfica procura compreender como se dão essas relações em seu contexto e em que sentido revelam uma cultura construída com base na escola. (FRANCO E GHEDIN, 2008, p. 203).

A etnografia escolar permite um processo de interpretação que tem a possibilidade de compreensão do outro, daquilo que os sujeitos de verdade 
são, estando ligado a um modo de perceber o mundo do outro ou de treinar o olhar para aprender como as pessoas agem sobre algo. Segundo André (2000, p. 28-30), a etnografia é a descrição de um sistema de significados culturais de um determinado grupo.

Assim, segundo a autora, podemos também trabalhar com três fases, ou seja, etapas que marcam a construção do processo metodológico, necessário para organização da pesquisa. Elementos estes que permitem caracterizar na seleção e na definição de problemas, a escolha do local da pesquisa; sistematização dos dados e explicação e interpretação da realidade.

Este texto está dividido em cinco momentos: o primeiro, cuja discussão gira em torno do ensino da cidade e do urbano na formação do cidadão; o segundo, que tem a cidade como conteúdo; o terceiro, em que a cidade é entendida enquanto representação espacial; o quarto, em que a aula é entendida a partir da discussão da didática histórico-crítica, e o quinto, em que se destaca a construção das aulas de Geografia da cidade e do urbano do Rio de Janeiro numa concepção histórica-crítica dos estudantes.

\section{O ensino da Cidade e do Urbano na formação cidadã}

Pensar o ensino e a construção de uma formação cidadã é uma forma de conscientizar os estudantes sobre seus direitos, suas ações para compreender a importância de lutar por igualdade social, ambiental e econômica.

Desde sua origem na Grécia Antiga, os cidadãos eram vistos como aqueles que viviam na cidade e tinham posses e negócios, ou seja, uma cidadania não para todos, mas para uma minoria, e que ao longo da história foi sendo "mudada" de acordo com as concepções filosóficas e teóricas do mundo. Até os dias atuais analisada por muitos como uma cidadania para o consumo, o que percebemos são concepções de cidadania que não condizem com aquilo que a escola deveria conceber para os seus estudantes.

Podemos dizer que a cidadania é a possibilidade de ter direito sobre seus direitos, ou seja, ter a consciência de refletir sobre as diferentes formas de práticas e exercícios de atos, para estar e ser no mundo e sobre ela aprender a ter a oportunidade de intervir junto com os outros, a defender suas ideias ou compreender como se estabelecem as contradições.

Para Cavalcanti (2011), o conceito de cidadania é pensado tanto do ponto de vista da vida pública e seus aspectos formais, quanto para os direitos e deveres no sentido ético, assim como o processo cultural com os 
direitos à igualdade. Para tanto, segundo a autora, a escola pode construir ações democráticas e ativas para recriar os processos histórico, social, econômico e cultural do município, do estado, do país. Além disso, trabalhar conjuntamente com as práticas socioespaciais dos estudantes para que eles tenham consciência de seus espaços, ou seja, saibam ler os fenômenos que estão transformando seus espaços vividos e de outras escalas, de forma a saber intervir, conhecer seus signos e símbolos, e lutar por seus direitos de viver sobre ela.

Assim, pensar uma Educação Cidadã é uma possibilidade de transformação na forma de ensinar, uma vez que se reflete sobre as mudanças da vida socioespacial estabelecida pelos governos, pela produção do trabalho, pelos conflitos sociais, como também pelas práticas sociais dos passantes e de seus próprios habitantes de um determinado lugar.

Trabalhar com uma concepção de educação cidadã é analisar como as contradições da vida estão presentes em todas as relações na forma como vivemos, além de compreender as diferentes ideologias que se apresentam no processo de mudanças da forma como construímos nossas relações com o mundo (físico, econômico, social, político).

Busca-se, igualmente, analisar as situações práticas dos diferentes movimentos sociais, dos impactos da segregação espacial, para trabalhar as concepções do mundo e saber lutar. Assim, a escola é um lugar importante para promover atividades que permitam aos estudantes compreender o modo de viver, e também de intervir em suas diferentes escalas para que os movimentos de mudanças sejam constantes na prática socioespacial.

Pensar a cidadania espacial é permitir que estes estudantes possam analisar os fenômenos geográficos que fazem parte das suas práticas socioespaciais Couto (2011), pois eles habitam, são habitantes, circulam, vivem um mundo de maneira coletiva, mas também de forma individualizada. Portanto, eles caminham em diferentes tipos de espaço, organizam sua vida de acordo com as condições espaciais, dos objetos, das práticas sociais e políticas que estão materializadas em formas, estruturas e conteúdos de uma dada realidade.

Compreender os aspectos argumentados por Páges (2005) apud Martija et allí (2013, p. 31) como: a) construir um olhar sobre o mundo no sentido crítico; b) adquirir maturidade política ativa e participativa como cidadãos do mundo; c) trabalhar sobre os problemas sociais e políticos 
contemporâneos, d) aprender a debater, construir suas próprias opiniões para criticar, a escolher a analisar os fatos, dentre outros. Desse modo, é entender a importância de ensinar para a cidadania, e ajudar os estudantes no desenvolvimento de uma consciência espacial sobre as diferentes transformações do mundo contemporâneo e as possibilidades de leitura deste, devido à forma como as pessoas vivem em suas moradias e têm relações com elas e com os outros.

Ademais, ter a consciência de que um cidadão do mundo contemporâneo capitalista está relacionado não somente com a prática de consumo ou com a de mercadorias, mas também com os espaços de lazer, cultura, trabalho e luta por moradia.

Busca-se, igualmente, destacar a importância de se ter ciência acerca da construção histórica de seu lugar, para saber como as concepções socioespaciais e territoriais foram se transformando com as formas de ocupação e intervenções sobre as paisagens, sobre os povos e sobre o governo do país.

É fundamental conhecer e compreender também os problemas que cercam a vida cotidiana, como a pobreza, violência, criminalidade, desemprego, moradia, desigualdade social e outros, assim como aqueles que nela vivem, uma vez que por vezes na escola estes tópicos não são trazidos como impacto em suas territorialidades.

Assim também são as questões políticas, que por meio de suas leis e decretos para "organizar" o espaço transformam a forma de viver de uma dada população, como o direito à moradia, de ir e vir, de organização urbana das cidades, que desagregam e marginalizam grande parte da população; a luta de classe, do ambiente e de outros, que mostram a necessidade de trabalhar com as questões não somente nos aspectos nacionais - como estão nos currículos e nos livros didáticos -, mas também articulando com as práticas socioespaciais dos estudantes.

Desta maneira, estes podem aprender a debater e a criticar os problemas e situações que acontecem nos seus bairros, na sua cidade, ou até no seu país; através dos conteúdos e argumentos trabalhados na sala de aula, que os fazem entender os processos de transformações espaciais do mundo contemporâneo.

Trabalhar com as práticas socioespaciais é promover uma ruptura no ensino de geografia, segundo afirma Couto (2011), por meio da construção 
de metodologias de ensino que suscitam os exercícios reais de seus direitos e deveres sobre a compreensão do mundo em que vivem.

\section{Pensar a cidade como um conteúdo para ensinar Geografia}

A cidade é uma parte do espaço geográfico, logo, parte da vida cotidiana dos estudantes, do conteúdo da disciplina Geografia. Sendo assim, aquela está carregada de um conjunto de valores, conhecimento, capacidades e atitudes que levam o professor a ensinar o conhecimento a fim de garantir o desenvolvimento e a socialização dos estudantes. Portanto, os professores podem construir atividades didáticas para capacitar aqueles a analisar seus espaços, e compreender como a cidade pode ser trabalhada em aula.

A intenção é desenvolver as capacidades mais amplas que fazem parte da aprendizagem dos estudantes ao tratar do tema Cidade e Urbano, e seus outros conteúdos disciplinares. Portanto, o objetivo é promover as capacidades motoras ao elaborar atividades que proporcionem aos estudantes dialogarem entre si, além da questão da cidadania, ao oferecer conteúdos que construam identidades, como também a compreensão de seu espaço vivido.

A função do conteúdo se relaciona à consciência espacial e com ela, a formação do cidadão, possibilitando ao estudante uma visão de mundo, de realidade de vida. A ideia é que os sujeitos-estudantes a formarem uma consciência da espacialidade dos fenômenos vivenciados.

Pensar a cidade e o urbano como um conteúdo para ensinar Geografia a partir da educação cidadã, é desenvolver a compreensão das bases do lugar vivido por meio das práticas socioespaciais. Como também as relações globais e locais que se caracterizam por conta do mundo, em que os fluxos e as redes se estabelecem mais rápido, o significado do estudo da cidade e do urbano permite que os estudantes reflitam sobre as situações que passam em seus bairros e sua cidade, os problemas urbanos, ambientais, sociais, fluxos e redes, dos aspectos físicos, suas paisagens, seus patrimônios históricos, seus arranjos territoriais, que muitas vezes não são articulados no cotidiano escolar (Moreno, 2011).

Assim, o estudo da cidade tem uma questão vital, pois se conhece e pensa sobre ela por aqueles que vivem, andam, consomem suas práticas cotidianas, da ida ao centro para fazer seus usos mais complexos, como 
em seus bairros. Ademais, a cidade é um arranjo territorial complexo, no qual seus signos, símbolos de significados espaciais a compõem como tal.

Para Moreno (2011), pensar a cidade é parte de uma dinâmica do próprio espaço, pois as mudanças e consequências nas estruturas conceituais permitem construir um projeto local e nacional para sanar as necessidades dos cidadãos, dos homens e mulheres que vivem no urbano, mas que não conhecem o ambiente em que vivem. Por isso a importância de compreender as práticas socioespaciais na escola, pois assim se rompe a ideia de um conteúdo distante dos estudantes, aproximando-os destes.

Para Castellar (2011), o estudo deste tema nos oferece vários conceitos e conteúdos para pensar como educar os estudantes geograficamente: apreender as questões de concepção de "natureza" no urbano; analisar de maneira profícua o tipo e o uso dos solos e das bacias hidrográficas; construir exercícios cartográficos sobre a cidade, entender a regionalização e diferenciação dos bairros e seus objetos geográficos. Desta maneira, estudar as atividades econômicas internas ao urbano, as diferentes ocupações da cidade e os problemas urbanos que atingem a vida de seus habitantes.

$\mathrm{O}$ destaque para o estudo da cidade está em compreender como a cidade, tal como um espaço educativo, pode ensinar a todos a existência de um lugar de contradição socioespacial e ambiental. Rodríguez e Barrera (2011) destacam a importância do estudo da cidade e de aprender sobre ela para desenvolver a aprendizagem de diferentes temáticas, como as sociais, econômicas, de paisagem e outros, que resultam na formação do indivíduo.

Para os autores, estudar a cidade permite ao indivíduo ter diferentes conteúdos para aprender a ler e analisar os diversos processos que a cidade oferece, de modo a ser um cidadão ativo e conhecedor das situações que acontecem sobre a cidade.

As concepções de ensinar Geografia e a cidade, segundo Sacramento (2012, 2014), têm por objetivo pensar uma educação geográfica que possibilite articular os conceitos e os conteúdos na mediação do conhecimento, a fim de analisar espacialmente as diferentes concepções espaciais, que podem ser histórico-patrimoniais, ambientais, morfológicas; e também como função de escala, em que o cidadão atua como protagonista na construção do seu conhecimento. 


\section{A Cidade como uma representação do espaço geográfico}

A cidade é uma parte do espaço geográfico, o qual é transformado por meio da produção e da apropriação de representações criadas por seu imaginário dentro de um espaço concreto. Sendo assim, é um espaço contraditório, ou seja, constitui-se das relações socioespaciais complexas e dialéticas pela forma de produção e reprodução da luta de classe, criando, assim, diferentes espaços segregados, segundo afirma (Harvey, 1980).

O espaço social é marcado pela sociedade, que com suas práticas sociais possui múltiplos aspectos: econômico, político, cultural; os quais se entrecruzam, produzindo mudanças por conta da aceleração da globalização. Tais práticas estão imbuídas da relação material e objetiva da produção e das relações do trabalho, mas também da relação subjetiva com os diferentes significados (Lefebvre, 2001).

Segundo Harvey (1980), ao perceber a importância da análise sobre a forma espacial, talvez seja pertinente decifrar as mensagens que as pessoas recebem e passam de seu ambiente construído - suas atividades espaciais na cidade -. As complexas relações que se configuram - uma vez que a sociedade experimenta novas práticas sociais - estão em volta de novas experiências e transformações das formas espaciais, que se organizam significativamente com o contexto em que esta se encontra. As experiências espaciais são parte da sociedade complexa, e permitem as mudanças do espaço por meio das concepções sociais que são caracterizadas nessas experiências socioespaciais.

O homem ao produzir suas práticas com os outros, estabelece-se por meio de determinados elementos que permitem ao mesmo tempo, a edificação de seu comportamento social de uma espacialidade que é a cidade em que vivemos, e o ensino da cidade, que possibilita pensar o processo de organização espacial vivenciada diariamente pelos estudantes, que por vezes não compreendem a origem e as diferentes transformações das técnicas, das ações e das relações que a sociedade estabelece com a natureza e com ela mesma, por sua necessidade de criar espaços para realizar múltiplas atividades.

O estudo desses fenômenos faz compreender qual a dimensão didático-pedagógica e geográfica para estabelecer uma interação de ensinar e aprender, de forma a promover aos estudantes a formação cidadã, o saber relacionar os conceitos e conteúdos estudados com os aspectos socioespaciais do cotidiano. 
Para Cavalcanti e Morais (2011), os estudantes trazem consigo formas de pensar a cidade, porque andam e também vivenciam partes do urbano: os serviços, os equipamentos, a circulação, a infraestrutura em seus diferentes níveis; além de saber os diferentes lugares da cidade.

O entendimento sobre o espaço vivido na cidade possibilita a mediação das práticas socioespaciais - que estão na paisagem, no território -, para um olhar por detrás das aparências, mas percebendo e analisando a dimensão de como os lugares realmente são construídos. Desse modo, como seria pensar os elementos físicos que compõem a paisagem na cidade, como: relevo, solo, lugar, rios, os elementos técnicos, os objetos e outros fenômenos, os quais interveem e desenvolvem a leitura espacial sobre os conhecimentos geográficos para a percepção das dinâmicas das diversas cidades (Sacramento, 2014).

A cidade é compreendida como um objeto de estudo geográfico por vários autores, como Harvey (1980); Lefebvre (1999, 2001), Souza (2011), e outros; os quais analisam acerca das diferentes transformações que ocorreram ao longo do tempo, por meio de contradições socioespaciais, culturais, econômicas e técnicas das reorganizações espaciais de suas funções, formas, conteúdos e ações sociais. A cidade representa a obra da história construída por seus sujeitos, ou da ação da sociedade que vive, produz e reproduz esse espaço.

A cidade, em suas múltiplas relações sociais, econômicas, históricas e geográficas, exige uma clareza contínua da organização e estruturação das novas dinâmicas do espaço. Se a cidade é a mediação das ordens próximas e distantes, tem uma forma específica de produzir e reproduzir, pois se relaciona com a vida em grupo dos indivíduos, e também da sociedade, que é regida pelas grandes instituições que estabelecem diferentes maneiras de construir a cidade.

Assim, estudar a cidade se torna relevante para a compreensão da construção do conhecimento geográfico, pois esta é vista como uma obra de arte. Sendo assim, precisa ser estudada de acordo com seus referenciais espaciais, suas relações e suas produções, já que ela é sujeito de uma história única. Pensar a cidade e o urbano de sua localidade é destacar a importância da cidade como "um espaço social", um produto das relações sociais e um condicionante dessas relações. 
A cidade é parte da concepção humana da criação e organização de seu espaço, onde se constituem vários objetos e fenômenos para serem interpretados de diferentes formas e conteúdos. Como parte do espaço geográfico estão presentes signos, símbolos e informações culturais, sociais e econômicas, que estão localizados, distribuídos, identificados em seus lugares.

A construção da cidade se dá pela necessidade de estabelecer relações socioespaciais para a ação, movimento, circulação, caminhada, vivência pelos lugares, a fim de criar condições de produzir espaços para as diferentes atividades desenvolvidas com o objetivo de agrupar e assentar a sociedade e as diversas funções.

Segundo Souza (2011), depreender acerca da cidade é algo muito complexo, já que requer um corpo individual próprio, construído e pensado tanto pela origem dos seus elementos físicos, como sociais. Ela é um objeto com múltiplas formas e conteúdos, tendo assentamentos humanos produto das relações sociais diversificadas em todas as áreas de atividades -; além de uma numerosa rede de informações, organização econômica, social e política, que se torna mais densa por seus diferentes usos do solo, do processo de sofisticação da urbanização, das transformações socioespaciais, da criação de novos objetos, das necessidades sociais e das diferentes características.

No ensino da geografia, discutir a cidade em sua multiplicidade é promover articulação dos conceitos e conteúdos didáticos, com os fenômenos especializados em sua própria dinâmica da cidade.

Para Lefebvre (2011), toda cidade tem uma história, das pessoas e dos grupos que a constrói de acordo com as necessidades e as condições históricas de cada período. Assim, ela é criada pelas práticas socioespaciais dos diferentes contextos, ou seja, da construção da obra chamada cidade se estabelecem ações por dimensões espaciais pela sociedade com aquela, entre elas (cidade e sociedade) e entre os lugares.

Ao criar novas redes e ao organizar novos papéis, os objetos, as pessoas e a sociedade recriam a cidade no instante em que a modernizam e a tornam mais dinâmica, pois essa obra é produzida pelos agentes que a transformam, que se apropriam da natureza, a fim de organizar socialmente o espaço, formando novos fenômenos na cidade, como o urbano. Isto é fundamental para o desenvolvimento da cidade, pois é pela morfologia que se articula como criar e produzir os lugares. 
Pensar o espaço urbano, segundo Corrêa (1999), é entender a complexidade das diversas atividades comerciais, de serviços, de gestão das áreas industriais, das áreas residenciais distintas, que se encontram em diferentes tipos de espaços e se caracterizam de acordo com suas formas e conteúdos.

Assim, os problemas do espaço urbano estão na pobreza e na segregação residencial, como também na degradação ambiental, no sistema de tráfego (os fluxos), nos serviços básicos e outros. Estes afetam diretamente o meio ambiente, pois em várias cidades há a falta de rede de esgoto, obrigando as pessoas a despejarem seus dejetos em rios, encostas e mares, afetando tanto os animais como os humanos (Souza, 2011).

Trabalhar a cidade e o espaço urbano por meio de suas contradições da produção e consumo, da segregação dos espaços, assim como os elementos que a caracterizam, por meio de uma dinâmica com os estudantes se torna fundamental para a reflexão acerta da cidade.

Para Lefebvre (2001), a produção da cidade se manifesta pelas diferentes disputas entre classes sociais territorializadas, para reproduzir a vida social, transformando a paisagem como forma de obter moradia, lazer, trabalho, etc.; assim, configurando a vida urbana. Neste sentido, cada cidade tem sua forma espacial e sua importância nos cenários regional ou nacional.

Por isso, a Educação Geográfica pode estabelecer a formação cidadã por meio dos conteúdos geográficos para fazer com que este estudante compreenda sua espacialidade nessas dimensões, de forma a estimular sua capacidade cognitiva, e entender a cidade como um espaço educativo.

Assim, ensinar a cidade possibilita a compreensão do espaço, suas imagens, suas linguagens e práticas socioespaciais. É trazer uma concepção da cidade nas práticas dos estudantes para construir reflexões sobre suas próprias relações com este espaço, com os conceitos não somente da Geografia, mas também da História ou da Política.

Desta forma, articular com os estudantes a questão da sua cidadania, seu direito à cidade, moradia, lazer, educação, trabalho; de produzir, de caminhar, de vivenciar seus espaços, de manifestar sua cultura, e que todos somos agentes ativos em formação e em mudança no espaço urbano, e que temos direito de lutar como cidadãos, a fim de viver nossas práticas socioespaciais. 


\section{A aula como uma construção de uma Didática Histórico-Crítica no estudo da cidade}

A aula é de fundamental importância na articulação das ações didáticas, ou seja, na forma como os professores conduzem a organização e a produção do conhecimento escolar e por sua relação com seu objeto de trabalho: a mediação do saber. Segundo Santos (1996, p.53), "ação é próprio do homem. Só o homem tem ação porque só ele tem objetivo, finalidade. As ações resultam de necessidades naturais ou criadas. Essas necessidades: materiais, imateriais, econômicas, sociais, culturais, morais, afetivas, é que conduzem os homens a agir e levam a funções".

Este ato reflexivo é a concepção de como os professores criam estratégias para trabalhar com os conteúdos e os conceitos, para construção das práticas socioespaciais dos estudantes ao longo da organização dialógica com os conteúdos das disciplinas, por parte dos docentes.

A reflexão cria uma possiblidade de compreender as espacialidades por meio da leitura do mundo e como os estudantes - sujeitos - se convertem em leitores ativos dos diferentes lugares e escalas, para promover a cidadania (Páges, 2005, apud Martija et allí, 2013, p. 31).

Assim, a construção da mediação didática se estabelece nas concepções geográficas vinculadas com as práticas socioespaciais dos estudantes, as quais, segundo Gasparin (2002), conduzem a uma aprendizagem significativa. Por isso, para mediar o conhecimento é necessário saber transmitir alguma coisa ao outro, ou seja, construir meios que possibilitem ao docente desenvolver uma relação única com os estudantes.

Pensar uma Didática Histórico-Crítica para autores como Gasparin (2002), Saviani (2003), Libâneo (2004) e Wachowicz (1991), é possibilitar aos estudantes a apropriação do conhecimento para modificar a sua realidade vivida através de uma mediação crítica dos conceitos e dos conteúdos desenvolvidos em sala de aula.

Para esses autores, desenvolver uma forma didático-pedagógica de construção do conhecimento partirá da realidade social mais ampla dos estudantes, a fim de concretizar uma leitura crítica e reflexiva sobre um dado lugar. Desta maneira, pensar uma proposta de didática histórico-crítica é promover uma dialética do ponto de vista da própria aula, que precisa mudar as concepções de ensinar dos professores e do entendimento da própria aprendizagem. 
A Didática Histórico-Crítica dos conteúdos possui uma finalidade social, que para Gasparin (2002), deve ter os conteúdos integrados e aplicados do ponto de vista teórico-prático no dia a dia do estudante. Os conhecimentos didático-pedagógicos são relevantes para pensar os caminhos, os meios, as formas de como estabelecer a relação entre o saber e os estudantes. Por isso trabalhar com uma prática social de uma didática crítica por meio de um ensino que seja significativo, crítico e ativo para articular as práticas socioespaciais das cidades vividas dos estudantes.

Gasparin (2002) afirma que a didática é estruturada de acordo com estas concepções, ou seja, toda a aula é pensada a partir do viés crítico, buscando articular as vivências dos alunos (a prática inicial), até chegar aos conhecimentos científicos (a prática social dos conteúdos). Para isso, como já foi relatado anteriormente, o autor desenvolveu seu método didático organizando os caminhos necessários para a aprendizagem dos alunos.

Assim, para pensar o ensino da cidade a partir das concepções de Gasparin (2002) é preciso estabelecer algumas características didáticas de organização de uma aula por meio de uma didática histórico-crítica, a saber: a) Prática Social Inicial do Conteúdo - a relação dos conhecimentos prévios dos alunos e dos conhecimentos dos professores, relacionado sobre o que os alunos já sabem sobre o conteúdo; b) Problematização como pensar a prática docente por um viés social na construção da aula, na discussão sobre o conteúdo e as dimensões dos conteúdos a serem trabalhadas; c) Instrumentalização - as ações didático-pedagógicas para pensar a aprendizagem e os recursos a serem utilizados; d) Catarse - o pensar do educando sobre o processo de aprendizagem no viés social e e) Prática social final - como a aula posiciona o aluno a repensar os conteúdos para sociabilizar-se com o seu cotidiano.

Portanto, a mediação do conhecimento possibilita a realização didática de proposta de ensino na qual os estudantes são sujeitos, desenvolvendo uma visão de forma a ver o mundo e os fenômenos geográficos sociais e físicos organizados espacialmente. Igualmente, proporciona pensar um processo de formação cidadã no qual contribui de fato para uma reflexão sobre o papel dos estudantes neste mundo contemporâneo e global, como já destacado anteriormente. 


\section{A construção das aulas de Geografia acerca da cidade e do urbano} do Rio de Janeiro numa concepção histórico-crítica dos estudantes

As aulas apresentadas neste texto são referentes a seis turmas de escolas públicas no Estado do Rio de Janeiro, três localizadas no município de Seropédica e três no município de São Gonçalo. Todas foram desenvolvidas por três professoras de Geografia conforme a metodologia da etnografia escolar.

As aulas foram pensadas a partir das concepções dos estudantes sobre a cidade do Rio de Janeiro, porque é a maior referência histórica do Brasil durante os períodos colonial, imperial e grande parte da república, os quais aconteceram na cidade, tendo sido palco das grandes transformações na história do país. Além disso, é o lugar de referência tanto do ponto de vista local como mundial. Muitos estudantes moram na cidade e vivenciam suas mudanças e dinâmicas nesta. 
Ana Claudia Ramos Sacramento. El estudio de la ciudad y los ciudadanos: la clase como una intervención de enseñanza para enseñar a la geografía

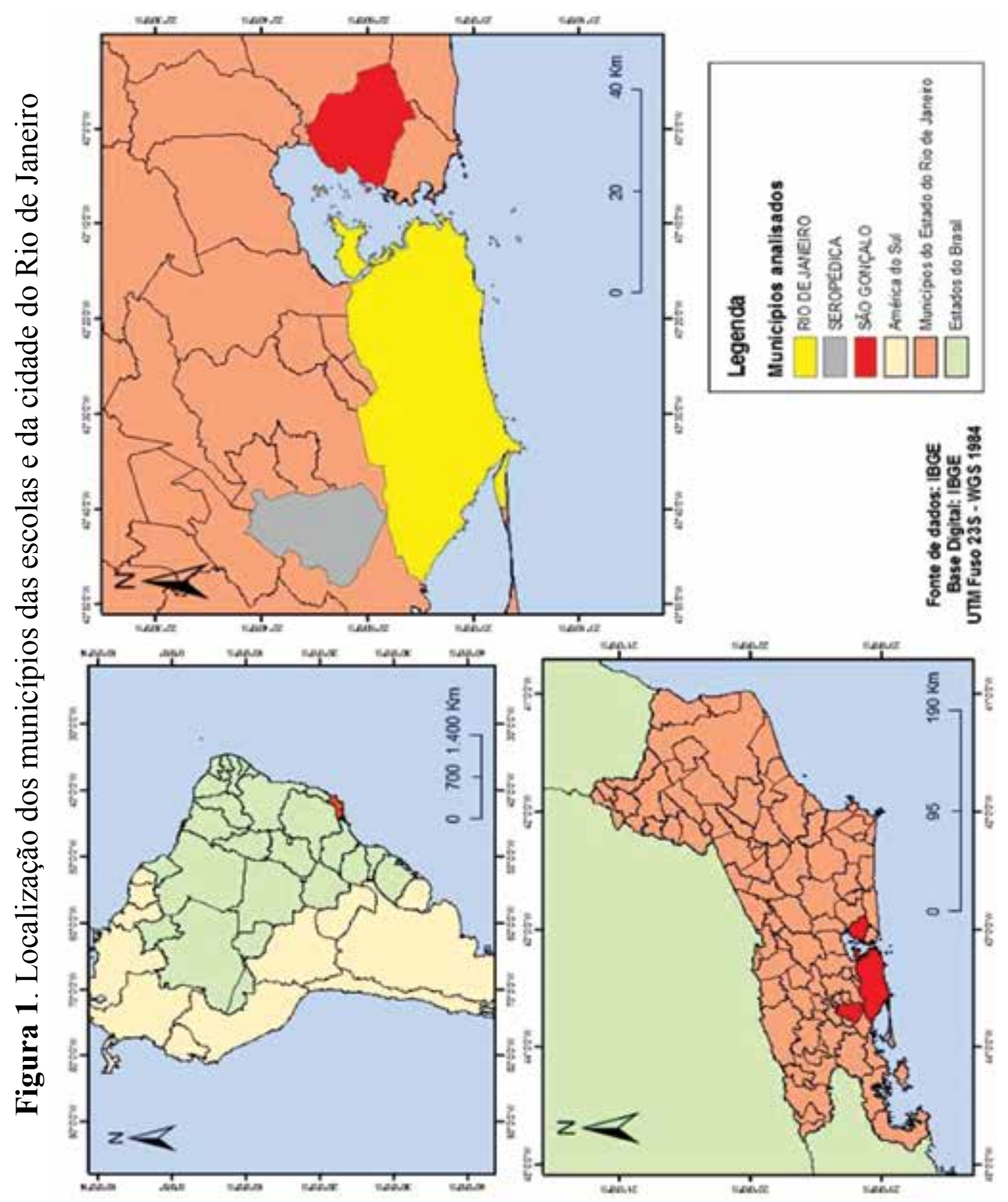


Para pensar uma aula mediada a partir da didática histórico-crítica, podemos dizer que:

Para iniciar a aula, faz-se uso da etapa 1, a prática social inicial, ou seja, o que os estudantes conheciam e vivenciavam sobre suas cidades. Para a compreensão dessa prática, foram formuladas perguntas orientadoras, como por exemplo: os estudantes conheciam ou compreendiam sobre a formação socioespacial de uma cidade? Por meio da discussão inicial, soube-se que para eles a cidade é um espaço onde as pessoas vivem, trabalham e estudam dada a necessidade da organização. Destacaram também os aspectos estruturais do urbano: a infraestrutura, os fixos e os fluxos, mostrando as diferenças dos bairros e das diferentes cidades onde eles vivem. As respostas foram diversas e auxiliaram no direcionamento dos conceitos e os conteúdos para desenvolver a aula.

Depois desse primeiro momento, foi usado o site $<\mathrm{http}: / /$ portalgeo. rio.rj.gov.br/EOUrbana/>, que é uma criação do Instituto Pereira Passos, órgão de Planejamento Urbano do Município do Rio de Janeiro, com o objetivo de trabalhar a origem de uma cidade e de suas transformações por meio das leituras dos mapas, das imagens e dos vídeos que retratam as diferentes paisagens que permitem perceber a organização espacial da cidade, conforme os objetos transformados ou não, devido aos aspectos políticos e sociais. O site é um recurso didático que possibilita discutir as diferentes mudanças ocorridas por estratificação das classes sociais, técnicas, políticas e econômicas (Abreu, 2011); ou seja, a organização da cidade e sua evolução são estruturadas por um conjunto complexo de intervenções das classes dominantes para a renovação da cidade dando origem às novas segregações espaciais como as favelas.

Na etapa 2, trabalhou-se com a problematização da temática, a qual analisa a concepção de cidade e de suas mudanças socioespaciais - o homem necessita criar os lugares para residir, trabalhar e viver -. Como e por que ocorreu a transformação das cidades e de seus bairros? e Qual o objetivo dessas transformações? foram algumas das questões levantadas para dar continuidade à aula. A aula se constitui a partir da análise das imagens do centro do Rio de Janeiro, pois a discussão foi realizada partindo-se da formação histórico-geográfica de Souza (2011), Abreu (2011), Sacramento $(2012,2014)$ sobre as transformações da Natureza e dos fenômenos 
naturais sobre a construção de uma obra, no caso, a cidade do Rio de Janeiro, como uma obra em construção. Estudou-se o relevo e suas formas: os lagos, as colinas, a praia, a enseada, as bacias hidrográficas, seus rios e afluentes. Assim, os estudantes compreenderiam que seus lugares de vivencia foram construídos de acordo com determinadas técnicas, mudança de uma paisagem natural por uma urbana, provocando-os a refletir como o espaço geográfico transforma as obras das sociedades em determinados períodos históricos. Assim, o processo de organização espacial da cidade do Rio de Janeiro provocou o desaparecimento das praias, de colinas, e de lagos, tendo novas dinâmicas de segregação socioespacial na cidade, como destaca Abreu (2011).

Em seguida, na etapa 3, houve a instrumentação, em que foi escolhida uma sequência de imagens: Largo da Carioca e Copacabana, pois seriam os lugares utilizados para a realização dos trabalhos de campo. Assim, foi solicitado aos estudantes analisar os elementos que ainda permanecem em cada imagem e os que foram mudando ao longo do tempo. Dessa maneira, os mesmos estudantes escreveram a comparação e a discussão sobre as análises das transformações e permanências das paisagens, como também perceberam as diferentes formas de viver nesta cidade. Por isso, para Abreu (2011) o papel do Estado foi determinante para a organização da cidade.

$\mathrm{O}$ autor caracteriza que as diferentes formas da política administrativa e econômica proporcionaram a organização espacial da cidade, pois cada agente utilizou-se das dinâmicas históricas e sociais para legitimar uma territorialidade tanto nas periferias como nas áreas centras e na zona sul da cidade, determinante para a segregação espacial. Para compreender a dinâmica urbana e o poder da centralidade e dos interesses da classe dominante, os estudantes trouxeram informações de seus bairros e de outros municípios. Desta maneira, articulamos essas transformações em diferentes cidades de vivência dos estudantes.

$\mathrm{Na}$ fase de catarse, etapa 4 , as discussões foram realizadas em equipe. Discutiu-se sobre quais seriam os conceitos percebidos pelos estudantes ao longo das classes: a) a paisagem natural e urbana - as mudanças e as permanências: o processo histórico-geográfico, ou seja, eles necessitam compreender o contexto e os meios de cada época; b) o processo de urbanização e de ocupação; c) o uso de diferentes técnicas, pois as imagens 
apresentavam casas e os edifícios com determinados estilos, que atualmente possuem tipos de materiais diferenciados; d) as diferentes mobilidades das pessoas, os cavalos, as carretas, as estradas, os carros; e) as questões de infraestrutura; f) as transformações do relevo, a bacia hidrográfica e o solo para desenvolvimento do assento humano; g) as desigualdades socioespaciais e as áreas da sociedade; h) planejamento urbano e plano diretor; i) violência urbana e j) a localização e o significado dos objetos, os símbolos e o uso da linguagem cartográfica, dentre outros.

Esses conceitos e conteúdos possibilitam a discussão acerca de como a cidade é uma construção humana - uma obra - que possui determinadas formas e conteúdos com determinadas características nas quais os bairros que a constituem se tornam únicas. Assim, a circulação, o uso do solo e outros, manifestam-se no processo urbano, formando uma rede de significados e símbolos sobre a cidade. Permite, assim, captar os modos de vida da população na cidade, e como os próprios estudantes têm um vínculo com essas diversas realidades.

$\mathrm{Na}$ etapa 5, a prática social final, os estudantes analisaram e perceberam quais foram as mudanças ocorridas em seus lugares de vivências, desde os conceitos e conteúdos na catarse a partir da contextualização, das discussões desenvolvidas na sala de aula, nas práticas sociais de sua cotidianidade, de modo a compreender que a cidade e os processos urbanos são contraditórios e dialéticos.

Para finalizar essa etapa, foi realizado um trabalho de campo com os estudantes na parte central do Rio de Janeiro e nos bairros do Leme e de Copacabana, que objetivava discutir as dinâmicas da cidade. Em seguida, eles desenvolveram um roteiro de campo e um vídeo de seus bairros.

O trabalho de campo teve como objetivo geral uma discussão teórico-prática das problematizações de uma parte da cidade, seus aspectos físico-naturais, sociais e culturais para que os estudantes analisassem diferentes realidades e por meio destas, pudessem compreender seus bairros.

Com os aspectos observados no campo e nas aulas de forma grupal, os estudantes tinham que escolher seus conteúdos e conceitos para realização e trabalho de campo. Cada um tinha que explicar suas temáticas e seus significados desde o ponto de vista, tal como um cidadão espacial. A partir disso, os estudantes realizaram o trabalho de campo em seus bairros ou 
municípios, a fim de escreverem quais aspectos seriam importantes para pensar o espaço urbano.

Eles trabalharam coletivamente na construção do roteiro de campo e durante a apresentação final na aula, podemos perceber diferentes perspectivas por parte dos subgrupos: uns trabalharam a parte ambiental; outros a histórica; outros a comercial e outros, a parte residencial.

Os estudantes também apresentaram os vídeos construídos por eles para mostrar aos outros e às professoras os lugares onde trabalharam. Muitas discussões e perguntas foram planejadas, mas o mais importante foi a tomada de consciência acerca da importância do estudo da cidade e do urbano do ponto de vista da formação cidadã, e da compreensão do que ocorre em sua cidade e bairro por meio de uma observação geográfica.

\section{Considerações finais}

A escola, com todas essas mudanças contemporâneas, deve ser o espaço no qual os estudantes precisam ter, compreender e dar sentido aos conceitos e conteúdos geográficos nas suas práticas cotidianas a fim de refletir acerca da cidadania. Esta precisa ser parte da formação do indivíduo, para que o mesmo se torne sujeito ativo no processo de sua aprendizagem para transpor o conhecimento para além da sala de aula, ou seja, que articule com as diferentes concepções de entendimento o mundo com todas essas características.

Uma destas é trabalhar como a cidade vem sendo um espaço vivenciado pelos estudantes, e que é percebida, concebida e vivida pelas necessidades dos agentes modeladores e transformadores, que precisam pensar e agir sobre os diversos usos de uma determinada parte desse lugar. As pessoas que vivenciam a cidade têm diferentes reações, desejos e ações ao caminharem sobre ela, por isso, precisam refletir sobre as diversas representações, bem como os signos e símbolos que se apresentam espacialmente, possibilitando diferentes formas de ler o mundo vivido e dar significado a ele.

Pensar a cidade para os cidadãos é uma possibilidade de articular aquilo que se ensina com as práticas sociais dos estudantes e trazer algumas dimensões dos fenômenos geográficos para pensar sobre os conceitos e os conteúdos, assim como os que articulam com a vida cotidiana. 
O objetivo de refletir acerca do desenvolvimento das aulas a partir da Didática Histórico-Crítica faz com que seja necessária uma mudança na concepção de ensinar dos professores e na articulação com os conhecimentos como uma forma de transformação do paradigma de aprendizagem. Assim, os estudantes podem ser os sujeitos ativos da produção do conhecimento a partir da própria realidade vivida.

Portanto, torna-se relevante o planejamento didático, o pensar acerca das novas metodologias, e dos objetivos e funções da Geografia atual, por meio da educação geográfica. A formação docente precisa estar relacionada com a preparação dos conhecimentos pedagógicos e específicos, para que a aprendizagem, a didática, a metodologia e o currículo, não sejam um simples "passar" do conteúdo, mas desenvolva no profissional o prazer de realizar seu trabalho, possibilitando uma formação cidadã crítica dos estudantes.

Construir as aulas numa concepção que envolva a prática social inicial e as implicações dos problemas levantados durante a construção do conhecimento possibilitam refletir sobre a importância de uma leitura crítica dos fenômenos geográficos, de modo a transpor os conhecimentos mediados na vida cotidiana.

Dessa forma, estudar e compreender a cidade e o urbano possibilita trabalhar e discutir a forma como os conhecimentos geográficos dão significados aos lugares vivenciados; contribui igualmente para tornar os estudantes sujeitos críticos na leitura dos fenômenos, fatos e atos que acontecem ao redor na relação com o mundo, permite ainda que os estudantes consigam ler os espaços para além de uma visão simplista, mas efetivamente os fazem pensar sobre o mundo em que vivem.

\section{Referências}

Abreu, M. de A. (2011) A Evolução urbana do Rio de Janeiro. 4. ed. Rio de Janeiro: IplanRIO.

André M. (2000). Etnografia da prática escolar. 5. ed. Campinas, SP: Papirus.

Castellar, S. (2011). “A cidade como método de estudo na educação geográfica”. In: Lache, N. M. \& RODRIGUES, A. C. Ciudades Leídas Ciudades Contadas: La ciudad latino-americana como escenario didáctico para la enseñanza de la geografía. Bogotá: Universidad Distrital Francisco José de Caldas,153-170. 
Cavalcanti, L. S. (2011). A Geografia Escolar e a Cidade: ensaios sobre o ensino de Geografia para a vida urbana cotidiana. Campinas-SP: Papirus.

Cavalcanti, L. S. \& Morais, E. M. B. de. (2011). “A cidade, os sujeitos e suas práticas espaciais cotidianas. In: Cavalcanti, L. S. \& Morais, E. M. B. de (Org.). A cidade e seus sujeitos. 1aed.Goiânia: Editora Vieira, 01, 13-30.

Couto, M. A. C. (2011). Método dialético na Didática da Geografia. In: Cavalcanti, L. S.; Bueno, M. A. \& Souza, V. C. de. (Org.). Produção do conhecimento e Pesquisa no Ensino de Geografia. 1 ed. GoiâniaGO: Ed. da PUC Goiás, 27-44.

Correa, R. L. (1999). O espaço urbano. São Paulo: Editora Ática. Franco, M. A. S. \& Ghedin, E. Questões de método na construção da pesquisa em educação. São Paulo: Cortez, 2008. (Coleção Docência em formação. Séries saberes pedagógicos).

Gasparin. J. L. (2002). Uma didática para a pedagogia histórico-crítica. São Paulo: Autores Associados.

Harvey, D. (1980). A justiça social e a cidade. São Paulo: Editora Hucitec. Lefebvre, H. (2001). O Direito à Cidade. São Paulo: Centauro.

Lefebvre, H. (1999). A Revolução Urbana. Belo Horizonte: Ed. UFMG.

Libâneo, J. C. (2004). A didática e a aprendizagem do pensar e do aprender: a Teoria Histórico-cultural da Atividade e a contribuição de Vasili Davydov. Revista Brasileira de Educação. 27 (27), 5-24.

Martija, A. A., Lagomarsino, C. B., Sterquel, R. F. y Silva, V. S. (2012). "Formación ciudadana desde la perspectiva de la Educación Geográfica". In: Palacios, F. A. Formación Ciudadana desde la Educación Geográfica. Serena: Editorial Universidad de la Serena, 19-74.

Moreno, E. A. R, (2011) ¿Por qué una didáctica de la ciudad Latinoamericana? In: Moreno, N. L. et al. (org). Ciudades Leídas, Ciudades Contades. Bogotá: Editorial Universidad Distrital Francisco José de Caldas. 7-21.

Rodríguez, A. C.; Barrera, C. A. Z. (2011) Percibir y aprender el espacio de la ciudad en la ciudad. IN: Moreno, N. L. et al. (org). Ciudades Leídas, Ciudades Contades. Bogotá: Editorial UD (Editorial Universidad Distrital Francisco José de Caldas), 112-152. 
Sacramento, A. C. R. (2012). Diferentes Linguagens na Educação Geográfica da Cidade do Rio de Janeiro. Revista Continentes (UFRRJ), 1 (1), 97-118.

Sacramento, A. C. R. (2014). A mediação didática do estudo da cidade e o trabalho de campo: diferentes formas de ensinar geografia. In: Castellar, S. (Org.). Geografia Escolar: contextualizando a sala de aula. 1ed. Curitba: CRV, 103-118.

Santos, M. (1996). A Natureza do Espaço: técnica e tempo, razão e emoção. São Paulo: Editora Hucitec.

Saviani, D. (2003). Pedagogia histórico-crítica: primeiras aproximações. Campinas: Autores Associados.

Souza, M. L. de. (2011). ABC do Desenvolvimento Urbano. (6) Rio de Janeiro: Bertrand Brasil.

Wachowicz, L. A. (1991). O método dialético na didática. $2^{\mathrm{a} e d . ~ C a m p i-~}$ nas: Papirus. 